\title{
MEASUREMENT OF SETTLEMENT FORCES ON HORIZONTAL BEAMS BURIED IN SNOW COVER
}

by

\author{
Hideomi Nakamura and Osamu ABe
}

Shinjo Branch, National Research Centre for Disaster Prevention, Science and Technology Agency, Toka-Machi, Shinjo-Shi, Yamagata-ken, 996 Japan

\section{ABSTRACT}

Settlement force of a snow cover acting on horizontal beams $0.8 \mathrm{~m}$ high on the ground has been measured using electric force gauges since winter 1974/75, to understand mechanisms of settlement force generation. Shapes of cross-sections of the beams were rectangular, square, equilateral triangle and triangular with a $37^{\circ}$ vertical angle. From the measurements, it was found that the magnitude of the settlement force acting on a beam did not depend upon the shape of cross-section when snow depth was smaller than $1.3 \mathrm{~m}$, but in deeper snow it was smaller on the triangular than on the rectangular beam. When the surface of the snow cover turned into a crust, the settlement force increased from about $0.3 \mathrm{kN} \mathrm{m}^{-1}$ to $1.1 \mathrm{kN} \mathrm{m}^{-1}$. Physical properties of snow cover are important for quantitative estimation of the settlement force on a beam.

\section{INTRODUCTION}

Any structure on the ground which is buried in snow cover sustains force due to snow load on it and snow settlement around it. We call this force settlement force of snow, and structures such as fences and guard-rails are sometimes destroyed by it when buried in snow cover.

In Japan, the settlement force on stakes or beams has been measured by many researchers (eg Amano 1943, Shidei and Takahashi 1949, Shoda 1953, Kobayashi and others 1976) mainly in Niigata prefecture of Hokuriku district, which is a rather warm area among the snowy regions of Japan (Figure 1). But in colder areas, as in Shinjo, few systematic measurements of settlement force have been carried out. Furthermore, settlement force is supposed to depend on the snow properties, and although the Japanese islands are small, snow properties vary from place to place. For these two main reasons, settlement force of snow cover onto horizontal beams has been measured since winter $1974 / 75$ in the test field of the Shijo Branch of the

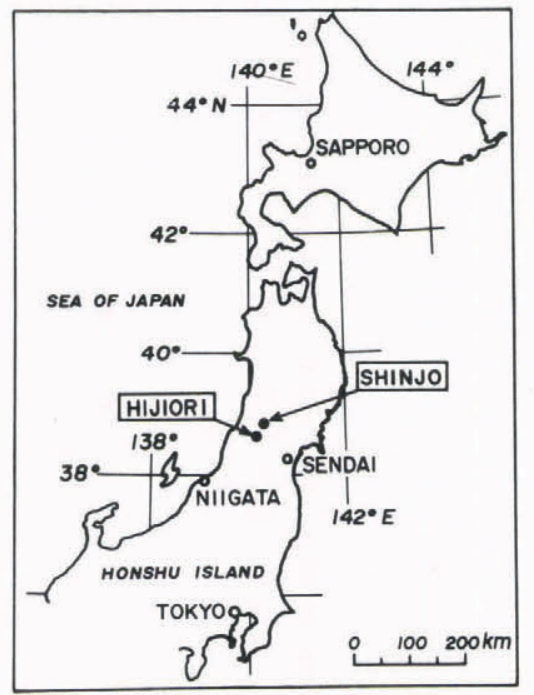

Fig.1. Locations of two experimental sites in north Japan.
National Research Center for Disaster Prevention, and since winter $1978 / 79$ at the Hijiori experimental site. The maximum snow depths on the ground at Shinjo and Hijiori experimental sites are, on average, $1.5 \mathrm{~m}$ and $4.5 \mathrm{~m}$, respectively,

\section{APPARATUS}

Cross-sections of beams used in this research were rectangular, square, equilateral triangular and triangular with a $37^{\circ}$ vertical angle (Figure 2). The height of all beams is $0.8 \mathrm{~m}$ above the ground, and the horizontal width of all beams is $0.1 \mathrm{~m}$. Each beam consists of three horizontal parts, each of length $1.0 \mathrm{~m},(2.0 \mathrm{~m}$ at Hijiori $)$, and settlement force onto the middle part only was measured by an electric force gauge fixed to a support, as shown in Figure 2. A penetrometer consisting of a steel corn and an aluminum plate was also inserted between the horizontal bar of the beam and another support, in case of failure of the electric gauge.

\section{RESULTS AND DISCUSSION}

Four examples of varying settlement forces, obtained from measurement of winter 1980/81 at both experimental sites, are shown in Figure 3. Force increases with increasing snow depth, and begins to decrease a few weeks later after the snow depth reached its maximum (as reported by Shōda 1953). Sudden sharp increases of force were observed at the end of the winters $1980 / 81$ and $1983 / 84$ at Hijiori only. Reasons for these are not yet clear, but as shown in Figure 3 , they appeared in the melting season only. Therefore they might be due to crust formation (see below).

Increment of settlement force onto a beam due to increase of the snow depth is shown in Figure 4, in comparison with the maximum force under maximum snow depth. Osada and others (1975), analyzing settlement force data measured at Niigata prefecture, proposed an equation to estimate maximum settlement force on a rectangular horizontal beam from maximum snow depth only; their relationship between force and maximum snow depth is shown in Figure 4 by a dashed line. The magnitude of maximum settlement force on rectangular and the square-section beams, measured each winter, is in good agreement with values calculated from Osada's equation when snow lies thinner than about $3 \mathrm{~m}$ on the ground.

Settlement forces acting on the two kinds of beams of triangular section were smaller than on the rectangular beam; similar results were previously observed by Suto and Nakamata (1970). From more detailed analysis of our measurements we found that forces on the triangular beams were almost equal to those on rectangular beams when snow depth was lessr than about $1.3 \mathrm{~m}$ : in deeper snow forces were smaller on triangular than on rectangular beams.

We found also that the settlement forces increased on a cold night, (Figure 5). Although it was warm in the daytime on 11 March 1983, (maximum air temperature: $\left.7.7^{\circ} \mathrm{C}\right)$, the night became colder and air temperature dropped to $-7.6^{\circ} \mathrm{C}$ in the early morning of 12 March. The snow cover surface turned to a hard crust as air temperature fell, the thickness of the crust reaching $15 \mathrm{~cm}$ at $7.35 \mathrm{am}$. Settlement force increased with the growth of the crust as shown in Figure 5. When the crust was cut off 


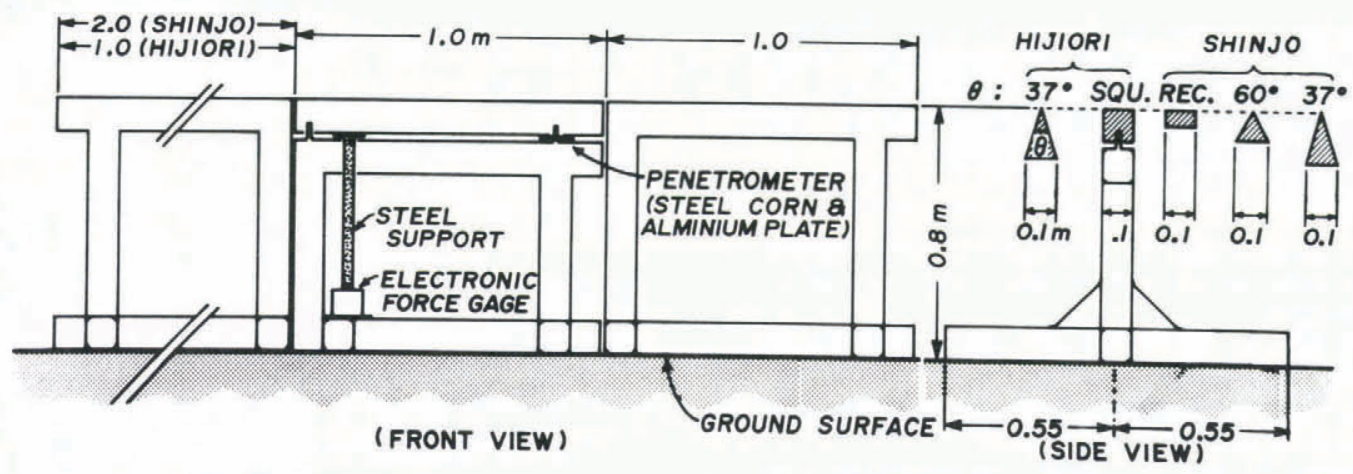

Fig.2. Horizontal beams with force measurement devices, and cross-sections of different types of beams.
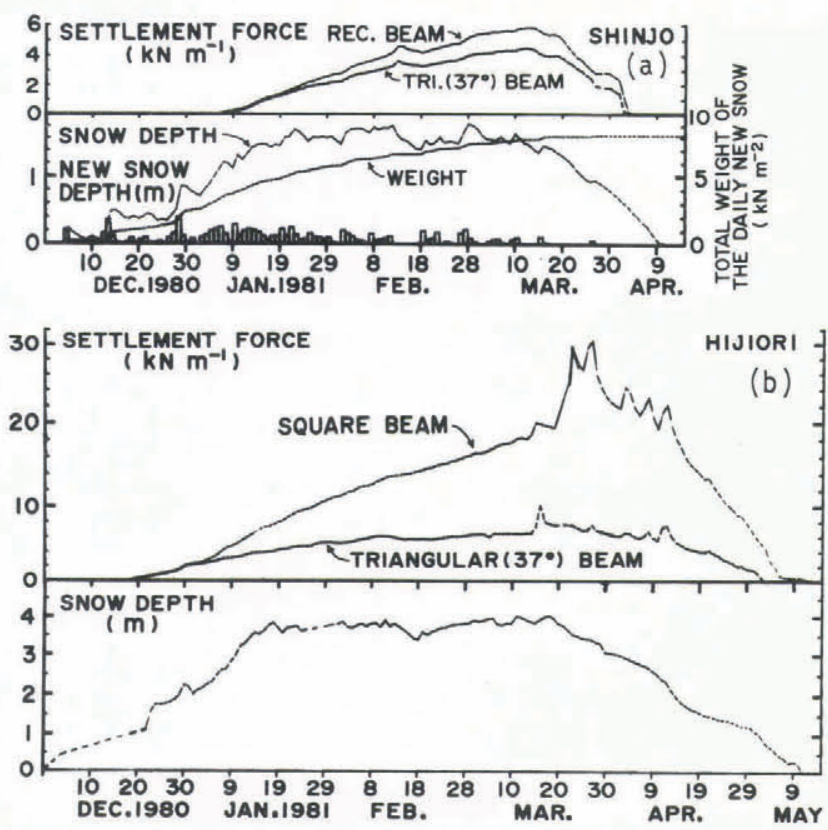

Fig.3. Daily change of settlment force on two different types of beams in comparison with three parameters, snow depth, daily new snow depth and total weight of the daily new snow depth: in Shinjo (a) and Hijiori (b).

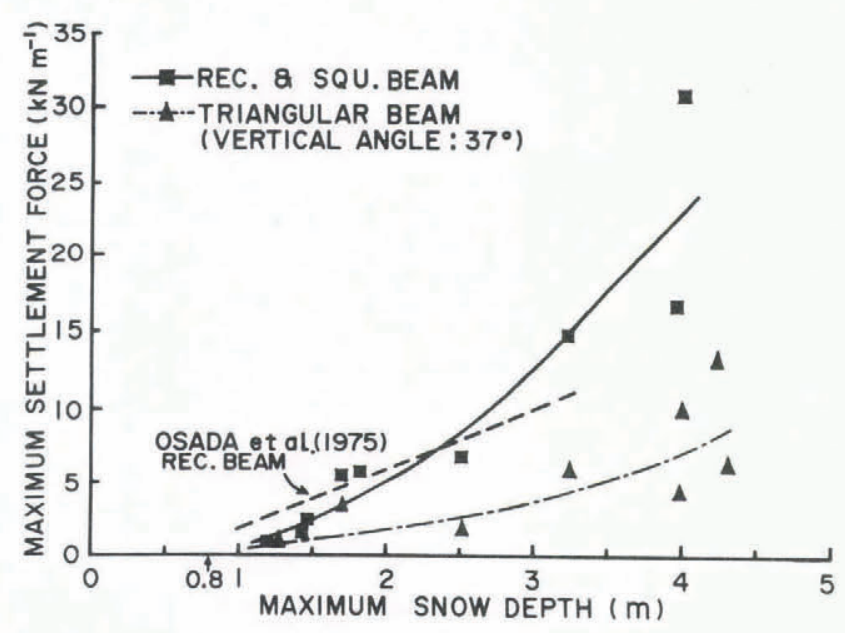

Fig.4. Increase of settlement force on a beam $0.8 \mathrm{~m}$ above the ground, due to increase of snow depth, seen in comparison of maximum force with maximum snow depth.

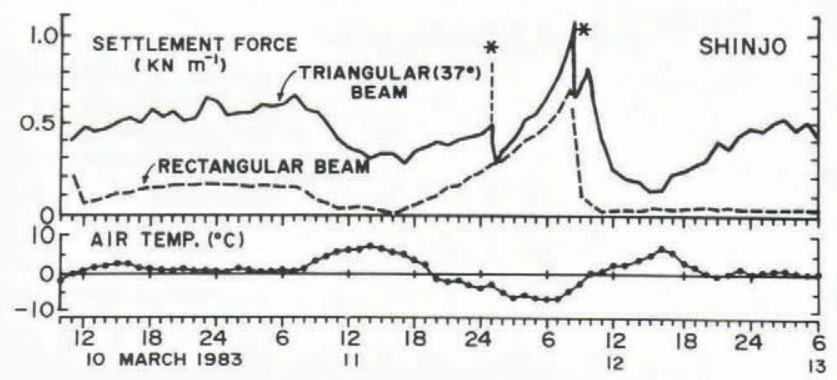

Fig.5. Changes in settlement force and air temperature at the Shinjo experimental site. Asterisks indicate the time when the hard crust layer adjacent to a triangular beam was cut, ie at 01:12 am and 08:28 am on 11 March 1983.

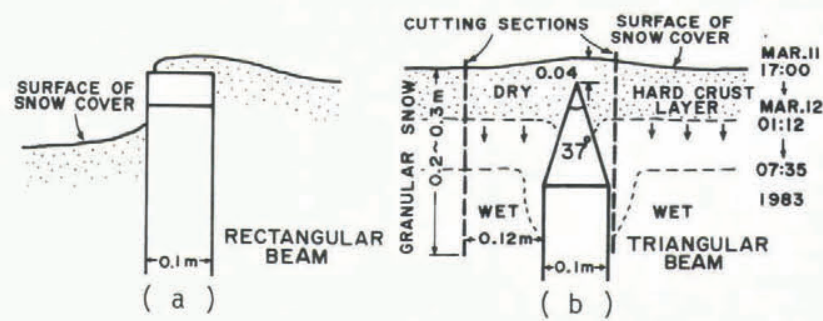

Fig.6. Cross-section of snow cover adjacent to rectangular (a) and triangular (b) beams, and growth of the hard crust layer adjacent to the triangular beam. Downward arrows indicate the growth direction of the crust layer.

along the beam of triangular section, (Figure 6b), settlement force decreased suddenly by $200-300 \mathrm{~N} \mathrm{~m}^{-1}$ (Figure 5). So it is considered that the growth of the crust layer on the beam caused the increment of the settlement force.

A similar process of bridging was derived through computer analysis of snow settlement, ie the increase of the settlement force from snow densification of a snow layer within the snowpack (Lang and others 1984).

\section{CONCLUSIONS}

Settlement forces acting upon beams $0.8 \mathrm{~m}$ above the ground were almost equal on beams of triangular or rectangular section in snow up to about $1.3 \mathrm{~m}$ deep. In snow deeper than this, forces were less on triangular than on rectangular beams. Settlement forces increased without further snowfall when the surface of wet snow cover turned into a crust.

From these observational results we conclude properties of the snow cover are an important factor in estimating settlement forces on beams, and need to be examined accurately and quantitatively.

\section{ACKNOWLEDGEMENTS}

The authors thank Professor T E Lang of Montana State University for his critical reading of the manuscript 
and Dr T Nakamura, director of Shinjo Branch, NRCDP, for his comments on daily changes in settlement force observed in his measurement, and also thank Drs $M$ Higashiura and $\mathrm{N}$ Numano of Shinjo Branch, NRCDP, for their help in measuring weight of daily snowfall.

\section{REFERENCES}

Amano I 1943 [Settlement force of snow cover.] Seppyo (Journal of the Japanese Society of Snow and Ice) 5(11): 357-368 (in Japanese)

Kobayashi K, Onuma T, Takahashi K 1976 [Studies on the snow damage of fruit-trees caused by settling force.] Bulletin of the Hokuriku National Agricultural Experiment Station 19: 179-207 ( in Japanese)

Lang T E, Nakamura H, Abe O 1985 Settlementforce on a beam in snowpack by computer modeling. Annals of Glaciology 6: 95-99

Osada T, Mikazuki S, Kobayashi T 1975 [Snow pressure acting upon a fixed beam under the snow by total of daily new snowfall depth.] Research Notes of the National Research Center for Disaster Prevention: 1-36 (in Japanese)

Shidei T, Takahashi K 1949 [Settlement force of snow cover.] Seppyo (Journal of the Japanese Society of Snow and Ice) 11(2): 76-86 (in Japanese)

Shoda M 1953 [Studies on settling force of deposited snow.] Researches on Snow and Ice 1: 136-154 (in Japanese)

Suto I, Nakamata S 1970 [Settlement force on beams of the rectangular shape and the triangular shape which vertical angles are $53^{\circ}$ and $18^{\circ}$.] Proceedings of Annual Meeting of Japanese Society of Snow and Ice: 39 (in Japanese) 